\title{
Analysis of the Effects from Adding Propeller Boss Cap Fins to Skewed Propeller Performance With CFD Methods
}

\author{
Irfan Syarief Arief ${ }^{1}$, Achmad Baidowi ${ }^{2}$, Anson Novendra Pradana ${ }^{3}$ \\ (Received: 14 August 2020 / Revised: 24 June 2021 / Accepted: 25 June 2021)
}

\begin{abstract}
Increased propeller efficiency can help to reduce fuel usage. The higher the efficiency, the less energy is wasted. Ships with high propeller efficiency may be able to provide more thrust while using less fuel. Propeller Boss Cap Fin (PBCF) installation is one of the solutions for improving propeller efficiency that is ideal for a submarine. PBCF may lower the submarine's energy usage, allowing it to recharge its batteries less frequently. According to certain studies, PBCF can boost propeller efficiency by $7 \%$ while lowering noise levels by nearly 6 decibels (dB). The impact of PBCF phase lag variation on skewed propeller performance and flow will be the subject of this article. CFD simulation using phase lags of $0,12.86,25.72$, and 38.58 will be used in the study. The simulation shows that PBCF can improve propeller efficiency while lowering propeller torque. Even though all phase lag modifications show a reduction in propeller thrust. On its hub vortex, they also reveal the existence of distraction.
\end{abstract}

Keywords — CFD, performance, propeller boss cap fins.

\section{INTRODUCTION}

$\mathrm{O}$ ver time the technology that discusses the propulsion system has been quite significant progress. Various ways have been done to improve the performance of a propeller to achieve the best efficiency so that it can reduce fuel consumption. With reduced fuel consumption the operational cost to operate the vessel will also decrease. Besides, increased efficiency can also reduce the carbon dioxide emissions produced by the main engine. The International Maritime Organization (IMO) notes that in 2013 the maritime world generates carbon dioxide emissions by 870 million tonnes or about $2.7 \%$ of global emissions [1].

To improve the energy efficiency of the propeller required a supporting component that is energy-saving devices. One of the most popular energy-saving devices is Propeller Boss Cap Fins (PBCF). In previous studies, it proved that the addition of $\mathrm{PBCF}$ can increase propeller efficiency by $7 \%$. The addition of PBCF is also capable of lowering the noise generated by the propeller up to $6 \mathrm{~dB}$ [2].

The added efficiency of the installation of Propeller Boss Cap Fins (PBCF) is also very useful for shipswarships, especially submarine-type battleships. Submarines generally use skewed propeller-type propellers and electric propulsion that use the battery as the main power storage. With increasing efficiency, the

Irfan Syarief Arief, Department of Marine Engineering, Institut Teknologi Sepuluh Nopember, Surabaya 60111, Indonesia, Email : irfansya@its.ac.id

Achmad Baidowi, Department of Marine Engineering, Institut Teknologi Sepuluh Nopember, Surabaya 60111, Indonesia, Email : ahmadbai@gmail.com

Anson Novendra Pradana, Department of Marine Engineering, Institut Teknologi Sepuluh Nopember, Surabaya 60111, Indonesia, Email : ansonnovendra@gmail.com use of battery power will be more efficient. Therefore, the submarine can dive in the water for longer without having to ride on the surface to recharge the battery.

\section{A. Propeller}

Propeller is one part of the propulsion system on the ship. A propeller is a tool used to convert the enginegenerated power of rotation in the form of rotational motion into a thrust or thrust force that keeps the ship moving forward.

Under normal operating conditions, the propeller will rotate clockwise when viewed from the aft of the vessel. The edges of the propeller leaf front are called leading edges, while the reverse side is called the trailing edge. The surface of the propeller leaves visible from the backside of the ship is called face, while the front ship is called back [3].

In certain cases, a vessel will be designed using another type of propeller in hopes of improving performance. Until now, the type of propeller is differentiated into 11 types of Fixed Pitch Propeller (FPP), Controllable Pitch Propeller (CPP), Contracted Loaded Tip (CLT) Propeller, Contra Rotating Propeller (CRP) Ducted Propeller, Propeller Boss Cap Fins (PBCF), Adjustable Bolted Propeller (ABP), High Skew Propeller, Keyless Propeller, Solid Propeller, Surface Piercing Propeller [4].

\section{B. Skewed Propeller}

Skewed Propeller or also commonly called High Skew Propeller is a propeller that has a Skew angle of more than 25 degrees. In general, this type of propeller is applied to vessels requiring noise as low as possible as a submarine example so that their existence is not easily detected by the enemy. Because this type of propeller can reduce noise up to $48 \%$ when compared with a conventional propeller [2]. 


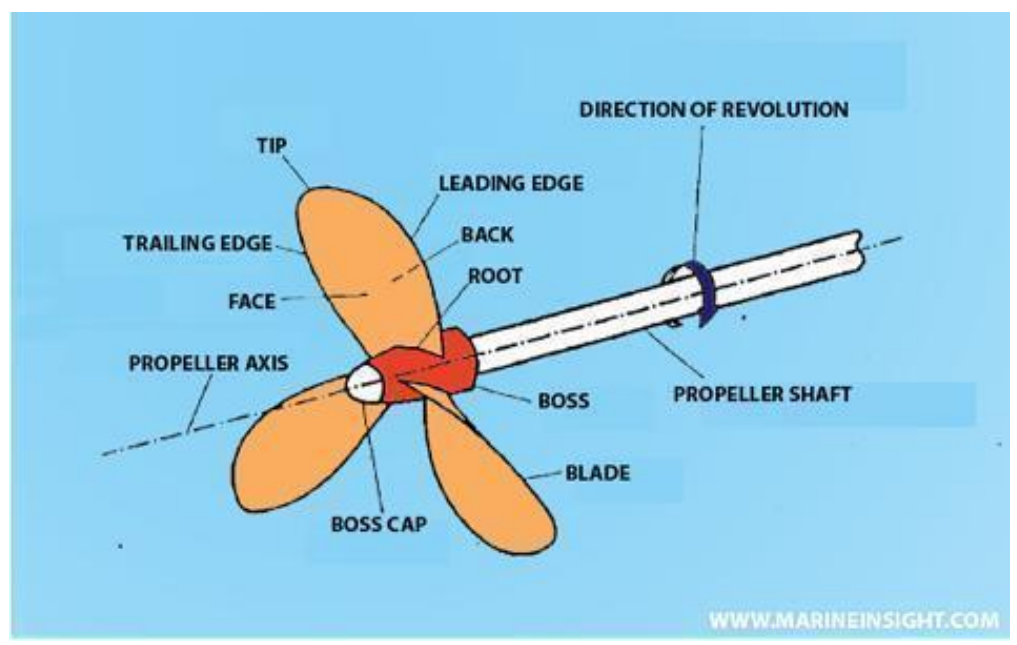

Figure. 1. The parts of the propeller [22].

\section{The Characteristics of Propeller Performance}

The characteristics of the propeller performance can be seen from the 3 components of KT (Thrust coefficient), KQ (Torque coefficient), and no (Propeller efficiency) in each variation $\mathbf{J}$ (Advance coefficient). To obtain these values, Open Water Test is required in advance.

To get the equation values above, it can be used several equations as follows :

$$
\begin{aligned}
& \mathrm{KT}=\frac{T_{\text {prop }}}{\rho \times n^{2} \times D^{4}} \\
& \mathrm{KQ}=\frac{Q_{\text {prop }}}{\rho \times n^{2} \times D^{5}} \\
& \mathrm{~J}=\frac{V_{A}}{n \times D} \\
& \eta_{\mathrm{o}}=\frac{T \times V_{a}}{2 \times \pi \times n \times Q}
\end{aligned}
$$

\section{Ship's Noise}

Noise is an unwanted sound from a business or activity at a specific level and time that can lead to human health problems and environmental comfort. Normal Noise is expressed in sound meter (DB) units. Noise on vessels with high intensity also causes a serious impact on the ship's crew (ABK) or passengers on board. Therefore, there needs to be a noise-canceling effort to be obtained from a healthy environment [5].

On the other hand, a lot of noise from commercial vessels can interfere with natural echolocation or the biosonar system of whales and dolphins that they use to find predators and prey. It can confuse them and disrupt their basic biological functions such as feeding and breeding [2].

Noise is also quite important for ships - battleships such as submarines. Where minimal noise is needed to make the position not easily tracked by the enemy radar system.
The noise on a submarine can be classified into 4 classifications as follows [6]:
1. "Very Quiet” Submarine
$<100 \mathrm{~dB}$
2. "Quiet”Submarine
3. "Noise" Submarine
$100-120 \mathrm{~dB}$
4. "Very Noise” Submarine
$120-140 \mathrm{~dB}$
$>140 \mathrm{~dB}$

\section{E. Propeller Boss Cap Fins (PBCF)}

Propeller boss can fins (PBCF) is a technology developed by Mitsui OSK. It consists of a short propeller mounted on the propeller boss which can transform the energy of the vortex hub into an additional thrust force and reduction of torque transmitted to the shaft. Reductions from the resulting vortex of the propeller hub can have an impact on low stern vibrations and low vane noise. Can also reduce erosion problems on the steering leaves [4].

The added Propeller boss can fin on conventional propeller can increase the propeller efficiency by up to $7 \%$ and reduce noise by up to $6 \mathrm{~dB}$ [2].

Taken from the daily data of the vessel with the same route and season, wind speed $8 \mathrm{~m} / \mathrm{s}$, and wave height of 3 $\mathrm{m}$ or more, the addition of PBCF on the propeller will also impact the fuel consumption of vessels [7].

\section{F. Hub Vortex}

The vortex Hub on the propeller has strong low pressure on the middle core. Low pressure on the nucleus leads to a decreased thrust. The difference in flow speed between the top and bottom of the surface of the propeller leaf generates a strong downward flow of the trailing edge on the propeller leaves. The combination of downward flow on each leaf will be a strong vortex hub. About $10 \%$ of energy is lost by this vortex hub.

A strong downward flow of the trailing edge of the propeller will be fixed by the PBCF fin to re-utilize the rotatable components so that the fin will produce a style (Qf) that reduces the torque (Q) of the propeller shaft by $3 \%$ and more. In addition, the thrust will increase by more than $1 \%[8]$. 

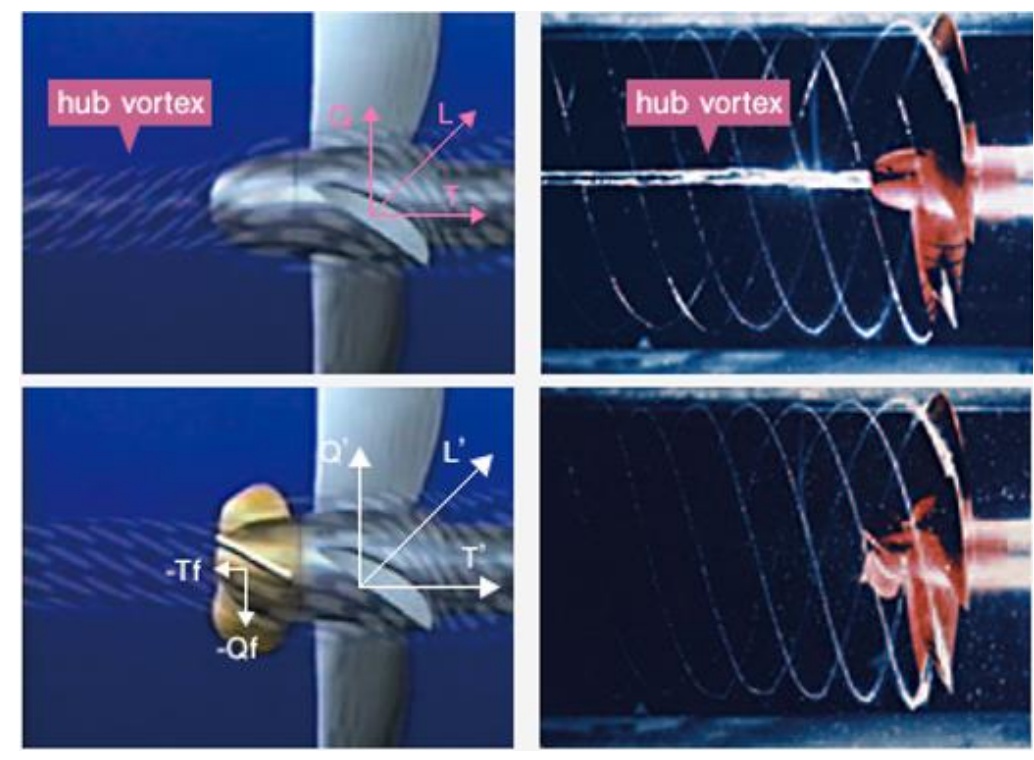

Figure. 2. Propeller flow before and after the addition of PBCF [8].

\section{G. Design Parameters of PBCF}

Based on the analysis generated on the design of PBCF parameters through open water propeller efficiency with experimental test and analysis based CFD, the design parameters of PBCF are as follows :

1. Number of fins

2. Radius ratio of PBCF to propeller ( $\mathrm{r} / \mathrm{R})$

3. Longitudinal Position (xPBCF)

4. Chord $\mathrm{PBCF}$

5. Rake angle PBCF (Inclination angle)

6. Pitch angle (Installation angle)

7. Phase lag angle

A

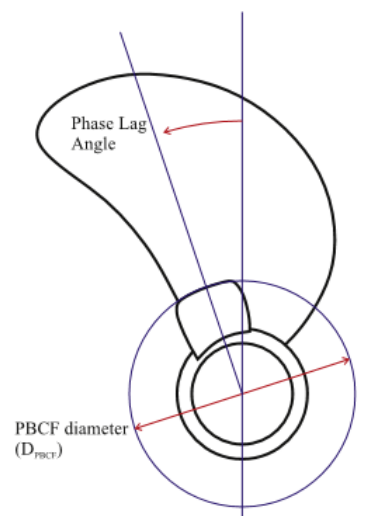

C

\section{H. Computational Fluid Dynamics (CFD)}

Computational Fluid Dynamics (CFD) is one of the branches of fluid mechanics that uses numerical methods and algorithms to solve and analyze problems related to fluid flow. The purpose of CFD is to accurately predict the flow of fluid, heat transfer, and chemical reactions in complex systems involving one or all of the above phenomena.

The CFD process is divided into three, pre-processing, computation, and post-processing. Pre-processing is the stage of data input which includes the determination of the domain and the boundary condition. At this stage also done
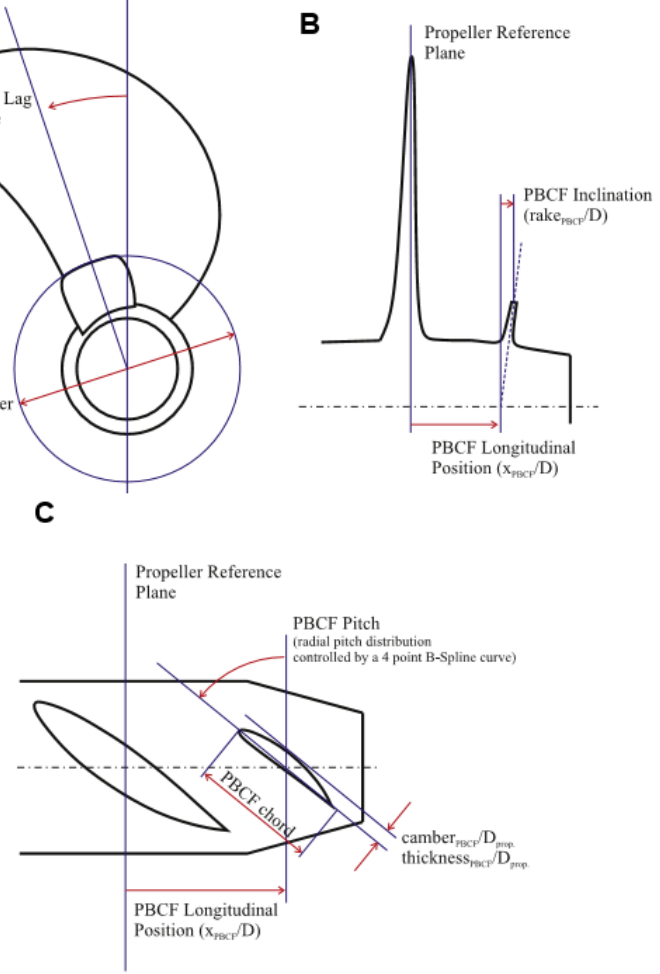

Figure. 3. Design parameters of PBCF [15]. 
meshing, where the analyzed objects are divided into a certain number of grids. Computation or processing is the process of calculating the data that has been inserted using the related equation iterative until the result obtained can reach the smallest error value. Post-processing is the result of a calculation at the processor stage that will be displayed in images, graphics, or animations [9].

\section{METHOD}

\section{A. Propeller Data}

This study used the propeller model that has been researched previously, the INSEAN E-1619 Submarine Propeller. Here are the data of the propeller INSEAN E1619 [10]:

$$
\begin{array}{llll}
- & \text { Diameter : } & 3250 \mathrm{~mm} \\
- & \text { Nb. of Blade : } & 7 \\
- & \text { (Ae/A0) : } & 0.608 \\
- & \text { Hub/ } \quad: & 0.226 \\
- & \text { P/D at 0.7R : } & 1.15
\end{array}
$$

\section{B. Propeller Modelling}

In this process, the 3-dimensional modeling of the INSEAN E-1619 Submarine Propeller model forms the existing 2-dimensional image and data. This modeling process uses the software Rhinoceros. Next, the 3dimensional model is saved with the file format Parasolid (. $\left.x_{-} t\right)$ as a condition for the CFD process in Numeca software.

\section{Meshing Process}

The meshing process is the process of identifying an object defined as a block - a small block or commonly known as a cell. This process is assisted with the software Numeca Hexpress. The more and more tightly the cell size the result of the simulation tends to be more valid. However, the time required for the simulation tends to take longer. The meshing process on the Numeca Hexpress has several stages such as domain creation, initial mesh, adapt to geometry, snap to geometry, optimize, viscous layer.

\section{Open Water Test Simulation using CFD}

In this process conducted an open water test simulation for each variation of the propeller model using the software Numeca FINEMarine. It is used to determine the performance characteristics of any variation of the propeller model such as thrust and torque values generated in each $\mathrm{J}$ (advance ratio). Some of the parameters to be set are general parameters, fluid model, flow model, boundary condition, body definition, body motion, mesh management, initial solution, control variables, output parameters.

\section{E. Result Validation}

In the validation process of the simulation results of the Open Water Test, the use of meshing validation to ensure the simulation results are accurate. The meshing validation is done by varying the number of cells of a model until it knows how many minimal cells are needed. Table 1 is the result of a simulated INSEAN E-1619 Submarine Propeller with 3 different cell variations.

TABLE 1.

Mesh VALIDATION

\begin{tabular}{cccc}
\hline Variation & $\begin{array}{c}\text { Number of cells } \\
\text { (Million) }\end{array}$ & $\mathrm{J}$ & Thrust (N) \\
\hline 1 & 2.4 & 0.6 & 458530.3 \\
2 & 1.8 & 0.6 & 457464.3 \\
3 & 1 & 0.6 & 446317.4 \\
\hline
\end{tabular}

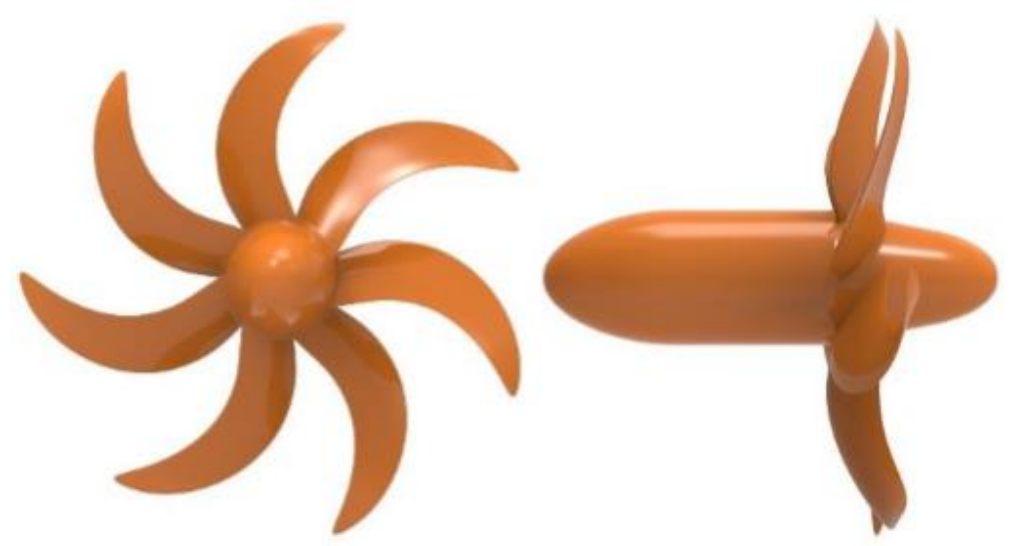

Figure. 4. 3D modeling of INSEAN E-1619 Submarine Propeller. 
The meshing validation can be assessed from the relative error value of variation 1 and Variation 2 (e21). The e21 value can be formulated as follows [11]:

$$
e_{21}=\left|\frac{f_{2}-f_{1}}{f_{1}}\right|
$$

Thus the value of e21 in this research is :

$\begin{array}{llc}\mathrm{f} 2(\text { Result from variation } 2) & = & 457464.3 \mathrm{~N} \\ \mathrm{f} 1 \text { (Result from variation } 1) & = & 458530.3 \mathrm{~N} \\ \mathrm{e}_{21} \quad=|457464.3-458530.3| / 458530.3 \\ & = & 0.00232 \\ & = & 0.232 \%\end{array}$

Kurt Mizzi in his research discussing the design optimization of $\mathrm{PBCF}$, using the value of e 21 at the thrust value of $0492 \%$ [12]. From the explanation and calculations above, it can be concluded that the cell amounted to $1.8-2.4$ million is considered valid and can be used for mesh standards in this research.

\section{F. Determination of PBCF Design Parameters}

For determining the design parameters of the $\mathrm{PBCF}$ model was obtained from the research suggestion has been done before.

Hsin in previous research explained that the number of PBCF fins should be equal to the number of the propeller from the propeller. As this research uses the INSEAN E1619 Submarine Propeller model which has 7 blades, the number of PBCF fins used by 7 fins [13].

$\begin{array}{rlll} & =(910-657) / 2 & \\ & = & 253 / 2=126.5 \mathrm{~mm} \\ \text { Chord } & = & \text { Span } / \text { Ratio STC } \\ & =126.5 / 0.23=550 \mathrm{~mm}\end{array}$

The study used NACA Airfoil Series in foil selection for PBCF. The National Advisory Committee for Aeronautics (NACA) suggests that the NACA Airfoil series is suitable to be applied to the ship's propeller is NACA 16 series [17].

The process of selection of foil is also influenced by Reynolds Number (Rn). Reynolds Number on the propeller can be formulated in the following formula [18]:

$$
R_{\mathrm{n}}=\frac{\rho n D^{2}}{\mu}
$$

The propeller model in this study was simulated in salt water with a temperature of $19^{\circ} \mathrm{C}$. Then Reynolds Number PBCF in the research was:
$\rho$ (density)
$=\quad 1025.07 \mathrm{~kg} / \mathrm{m}^{3}$
$\mathrm{n} \quad=\quad 3.8 \mathrm{rps}$
$\mathrm{D}($ Diameter of PBCF $)=0.91 \mathrm{~m}$
$\mu$ (Dynamic Viscosity) $=0.001103$ Pa.s
$\mathrm{Rn} \quad=\quad 1025.07 \times 3.8 \times\left(0.91^{2}\right) / 0.001103$

$$
=\quad 2,924,451.29
$$

Harold E. Cleary in his research on the Reynolds Number effect on the NACA 16 series airfoil explains that the maximum Reynolds Number of the NACA 16 series can reach more than 3.8 million [19]. With the calculation of Rn above, the NACA 16-006 series can be used for

Figure. 5. Geometry of NACA 16-006 [21].

PBCF Diameter can be identified using the PBCF radius ratio against the propeller $(\mathrm{R} / \mathrm{R})$. Based on a previous study by Lim who analyzed PBCF on a container ship, the best $R / R$ value that can be used is 0.28 [14]. Based on the explanation above, PBCF diameter is:

$\begin{array}{lll}\mathrm{D} \text { prop } & = & 3.25 \mathrm{~m} \\ \mathrm{r} / \mathrm{R} & = & 0.28 \\ \mathrm{D} P B C F & = & \mathrm{r} / \mathrm{R} \times \text { D prop } \\ & = & 0.28 \times 3.25 \\ & = & 0.91 \mathrm{~m}=910 \mathrm{~mm}\end{array}$

The previous research on PBCF's design by Stefano Gaggero suggested the axial position value compared to the propeller diameter (xPBCF/Dprop) of 0.17 [15]. Therefore, the value of $\mathrm{XPBCF}$ in this study is:

$\begin{array}{lll}\mathrm{D} \text { prop } & = & 3.25 \mathrm{~m} \\ x P B C F / \text { Dprop } & = & 0.17 \\ x P B C F & = & x P B C F / \text { Dprop } \times \text { D prop } \\ & = & 0.17 \times 3.25 \\ & = & 0.5525 \mathrm{~m}=552.5 \mathrm{~mm}\end{array}$

Izzul Fikri in his research that observed the effect of changing the ratio of span to chord (STC) PBCF on propeller C-Series explained that the best STC ratio is 0.23 [16]. Based on the explanation above, the span and chord dimensions of this study are:

Span $=(\mathrm{D} P B C F-$ Diameter Boss Cap $) / 2$
$\mathrm{PBCF}$ foil in this research.

A previous study by Lim made variations of a rake angle of $10^{\circ}, 0^{\circ},-10^{\circ}$ on PBCF. From the study came the results that the PBCF $0^{\circ}$ rake angle has better efficiency. So, this study used a rake angle PBCF $0^{\circ}$.

In addition to a variation of $\mathrm{R} / \mathrm{R}$ ratio and a rake angle, Lim in previous research also varied pitch angles to PBCF. The variation of the pitch angle used is $61.5^{\circ}, 66.5$ ${ }^{\circ}, 71.5^{\circ}$. From the study came the results that the angle of $61.5^{\circ}$ pitch has better efficiency [14].

Because each propeller has a different pitch (P/D) characteristic, then in this research, the author tries to add a variation of PBCF pitch angle whose value is assumed to equal to the pitch angle of the root propeller INSEAN E-1619 of $35^{\circ}$.

After the experiments on a variation of the pitch angle $\mathrm{PBCF} 61.5^{\circ}$ and $35^{\circ}$, obtained the result that the pitch angle of PBCF 350 has better efficiency results. So in this study used the pitch angle of PBCF $35^{\circ}$.

Determining the phase lag angle is crucial to PBCF. It is used to know the position of PBCF angles against the most optimal blade propeller so that $\mathrm{PBCF}$ can receive the resulting flow after passing the propeller blade in the right position. This study will use 4 variations of the phase lag PBCF angle with the following determination: 
TABLE 2.

VARIATION OF PBCF DESIGN

\begin{tabular}{ccccc}
\hline Variation & PBCF 01 & PBCF 02 & PBCF 03 & PBCF 04 \\
\hline phase lag $\left(^{\circ}\right)$ & 0 & 12.86 & 25.72 & 38.58 \\
pitch $\left(^{\circ}\right)$ & 35 & 35 & 35 & 35 \\
rake $\left(^{\circ}\right)$ & 0 & 0 & 0 & 0 \\
r/R & 0.28 & 0.28 & 0.28 & 0.28 \\
xPBCF $(\mathrm{mm})$ & 552.5 & 552.5 & 552.5 & 552.5 \\
Type of foil & NACA & NACA & NACA & NACA \\
Chord fin $(\mathrm{mm})$ & 16 & 16 & 16 & 16 \\
Nb. of fin & 550 & 550 & 550 & 550 \\
\hline
\end{tabular}
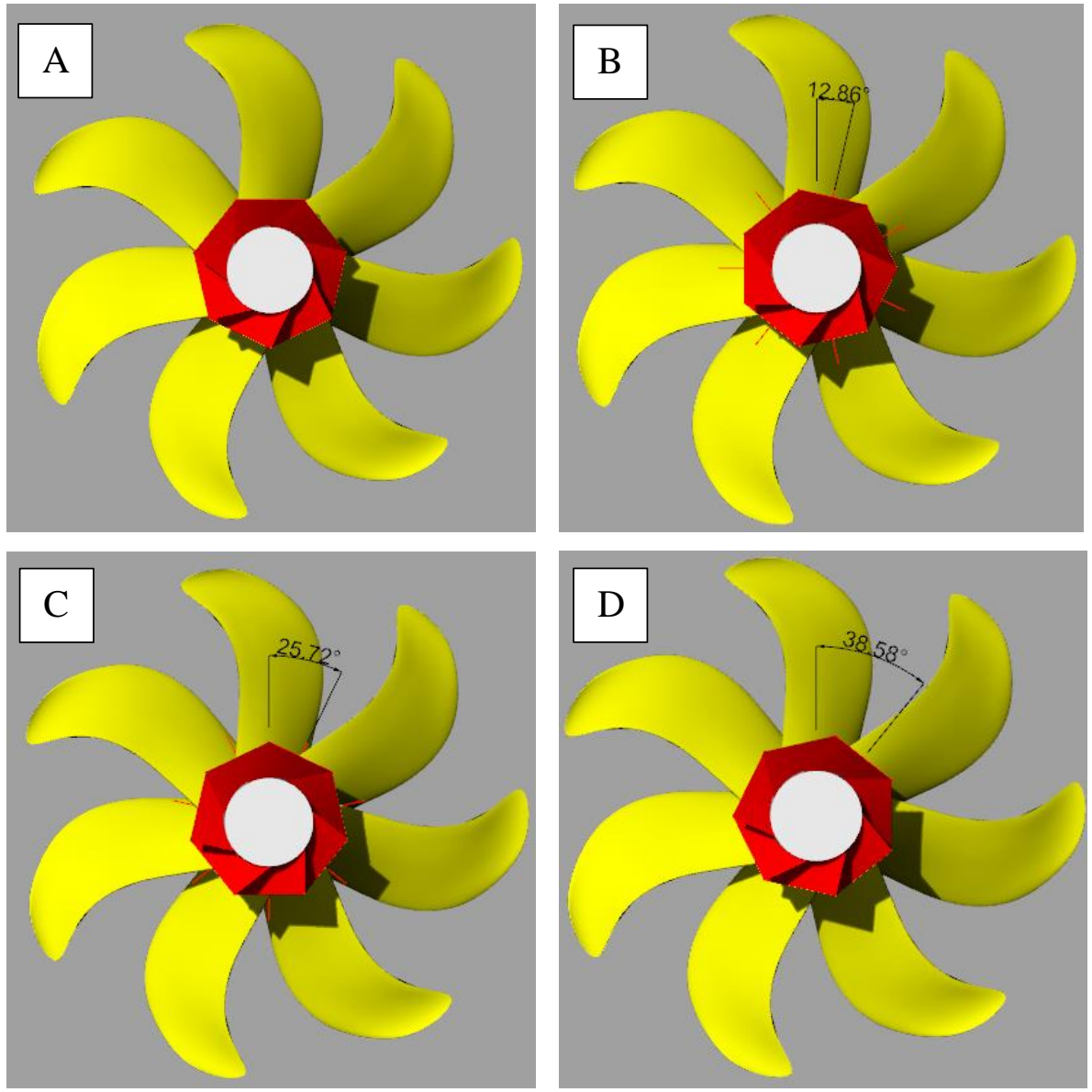

Figure. 6. PBCF 01 (A); PBCF 02 (B); PBCF 03 (C); PBCF 04 (D).

Nb. of propeller blade

$=7$

Angle distance between PBCF

$=$

$360^{\circ} / 7$

$51.43^{\circ}$

$51.43^{\circ} / 4$

$12.86^{\circ}$

So in this research used a variation of the phase lag PBCF angle with design parameters as in Table 2.

\section{RESULTS AND DISCUSSION}

\section{A. Performance Characteristics of INSEAN E-1619}

This study used several variations of the advance coefficient. According to the advice of ITTC in the open

water, the test procedure should be the propeller rotation (RPM) is kept constant to achieve reliable results [20]. The variations of the advance coefficient used in this study in Table 3. After open water test simulation of INSEAN E-1619, Obtained results as in Table 4.

\section{B. Performance Analysis of PBCF 01}

From Table 5, it can be concluded that variations of PBCF 01 thrust values tend to have decreased with an average of $-1,283 \%$. This is because the thrust value of $\mathbf{J}$ 1.0 drops drastically to- $8,526 \%$. However, the variations of $\mathrm{J} 0.2,0.4$, and 0.6 thrust values continue to increase. 
International Journal of Marine Engineering Innovation and Research, Vol. 6(2), June. 2021. 140-151 (pISSN: 2541-5972, eISSN: 2548-1479)

TABLE 3.

VARIATION OF ADVANCE COEFFICIENT

\begin{tabular}{cccc}
\hline $\mathbf{J}$ & RPM & RPS & Va $(\mathbf{m} / \mathbf{s})$ \\
\hline 0.2 & 228 & 3.8 & 2.470 \\
0.4 & 228 & 3.8 & 4.940 \\
0.6 & 228 & 3.8 & 7.410 \\
0.8 & 228 & 3.8 & 9.880 \\
1.0 & 228 & 3.8 & 12.350 \\
\hline
\end{tabular}

TABLE 4.

PERFORMANCE OF INSEAN E-1619

\begin{tabular}{cccccc}
\hline $\mathbf{J}$ & Thrust (kN) & $\begin{array}{c}\text { Torque } \\
(\mathbf{k N m})\end{array}$ & $\mathbf{\eta o}$ & KT & 10KQ \\
\hline 0.2 & 752.118 & 360.854 & 0.216 & 0.455 & 0.672 \\
0.4 & 613.161 & 318.674 & 0.398 & 0.371 & 0.594 \\
0.6 & 457.464 & 264.021 & 0.538 & 0.277 & 0.492 \\
0.8 & 282.653 & 193.470 & 0.605 & 0.171 & 0.360 \\
1.0 & 80.556 & 103.302 & 0.404 & 0.049 & 0.192 \\
\hline
\end{tabular}

TABLE 5.

PERFORMANCE OF PBCF 01

\begin{tabular}{|c|c|c|c|c|c|c|c|c|c|}
\hline \multirow[t]{2}{*}{$\mathbf{J}$} & \multicolumn{3}{|c|}{ INSEAN E-1619 } & \multicolumn{3}{|c|}{ Variation PBCF 01} & \multicolumn{3}{|c|}{ Increasement } \\
\hline & $\mathbf{T}$ & $\mathbf{Q}$ & $\eta_{0}$ & $\mathbf{T}$ & $\mathbf{Q}$ & no & $\Delta \mathrm{T}(\%)$ & $\Delta Q(\%)$ & $\Delta \eta(\%)$ \\
\hline 0.2 & 752.118 & 360.854 & 0.216 & 765.000 & 360.047 & 0.220 & 1.713 & -0.223 & 1.940 \\
\hline 0.4 & 613.161 & 318.674 & 0.398 & 618.778 & 317.709 & 0.403 & 0.916 & -0.303 & 1.223 \\
\hline 0.6 & 457.464 & 264.021 & 0.538 & 458.573 & 262.099 & 0.543 & 0.242 & -0.728 & 0.978 \\
\hline 0.8 & 282.653 & 193.470 & 0.605 & 280.501 & 189.410 & 0.613 & -0.761 & -2.098 & 1.366 \\
\hline 1.0 & 80.556 & 103.302 & 0.404 & 73.688 & 93.947 & 0.406 & -8.526 & -9.056 & 0.583 \\
\hline \multicolumn{7}{|c|}{ Average increasement } & -1.283 & -2.482 & 1.218 \\
\hline
\end{tabular}

TABLE 6.

PERFORMANCE OF PBCF 02

\begin{tabular}{|c|c|c|c|c|c|c|c|c|c|}
\hline \multirow[t]{2}{*}{$\mathbf{J}$} & \multicolumn{3}{|c|}{ INSEAN E-1619 } & \multicolumn{3}{|c|}{ Variation PBCF 02} & \multicolumn{3}{|c|}{ Increasement } \\
\hline & $\mathbf{T}$ & $\mathbf{Q}$ & $\eta_{0}$ & $\mathbf{T}$ & $\mathbf{Q}$ & $\eta_{0}$ & $\Delta \mathrm{T}(\%)$ & $\Delta Q(\%)$ & $\Delta \eta(\%)$ \\
\hline 0.2 & 752.118 & 360.854 & 0.216 & 764.754 & 360.000 & 0.220 & 1.680 & -0.236 & 1.921 \\
\hline 0.4 & 613.161 & 318.674 & 0.398 & 618.645 & 317.700 & 0.403 & 0.894 & -0.306 & 1.204 \\
\hline 0.6 & 457.464 & 264.021 & 0.538 & 458.551 & 262.109 & 0.543 & 0.237 & -0.724 & 0.969 \\
\hline 0.8 & 282.653 & 193.470 & 0.605 & 280.506 & 189.367 & 0.613 & -0.759 & -2.121 & 1.391 \\
\hline 1.0 & 80.556 & 103.302 & 0.404 & 73.624 & 93.876 & 0.406 & -8.606 & -9.124 & 0.571 \\
\hline \multicolumn{7}{|c|}{ Average increasement } & -1.311 & -2.502 & 1.211 \\
\hline
\end{tabular}

TABLE 7.

PERFORMANCE OF PBCF 03

\begin{tabular}{cccccccccc}
\hline \multirow{2}{*}{$\mathbf{J}$} & \multicolumn{1}{c}{ INSEAN E-1619 } & \multicolumn{1}{c}{ Variation PBCF 03 } & \multicolumn{3}{c}{ Increasement } \\
\cline { 2 - 10 } & $\mathbf{T}$ & $\mathbf{Q}$ & $\mathbf{\eta}$ & $\mathbf{T}$ & $\mathbf{Q}$ & $\mathbf{\eta} \mathbf{\Delta}$ & $\boldsymbol{\Delta} \mathbf{T}(\%)$ & $\boldsymbol{\Delta} \mathbf{Q}(\%)$ & $\Delta \mathbf{\Delta}(\%)$ \\
\hline 0.2 & 752.118 & 360.854 & 0.216 & 764.911 & 360.135 & 0.220 & 1.701 & -0.199 & 1.904 \\
0.4 & 613.161 & 318.674 & 0.398 & 618.901 & 317.862 & 0.403 & 0.936 & -0.255 & 1.194 \\
0.6 & 457.464 & 264.021 & 0.538 & 458.749 & 262.190 & 0.543 & 0.281 & -0.694 & 0.981 \\
0.8 & 282.653 & 193.470 & 0.605 & 280.506 & 189.403 & 0.613 & -0.760 & -2.102 & 1.371 \\
1.0 & 80.556 & 103.302 & 0.404 & 73.436 & 93.910 & 0.405 & -8.839 & -9.091 & 0.277 \\
\hline \multicolumn{4}{c}{ Average increasement } & & & -1.336 & -2.468 & 1.145 \\
\hline
\end{tabular}


TABLE 8.

PERFORMANCE OF PBCF 04

\begin{tabular}{cccccccccc}
\hline J & \multicolumn{3}{c}{ INSEAN E-1619 } & \multicolumn{3}{c}{ Variation PBCF 04 } & \multicolumn{3}{c}{ Increasement } \\
& $\mathbf{T}$ & $\mathbf{Q}$ & $\mathbf{\eta}_{\mathbf{0}}$ & $\mathbf{T}$ & $\mathbf{Q}$ & $\boldsymbol{\eta}_{\mathbf{0}}$ & $\boldsymbol{\Delta T}(\mathbf{\%})$ & $\boldsymbol{\Delta Q} \mathbf{( \% )}$ & $\boldsymbol{\Delta} \mathbf{\eta}(\mathbf{\%})$ \\
\hline 0.2 & 752.118 & 360.854 & 0.216 & 765.179 & 360.133 & 0.220 & 1.737 & -0.200 & 1.940 \\
0.4 & 613.161 & 318.674 & 0.398 & 618.828 & 317.746 & 0.403 & 0.924 & -0.291 & 1.219 \\
0.6 & 457.464 & 264.021 & 0.538 & 458.497 & 262.018 & 0.543 & 0.226 & -0.759 & 0.992 \\
0.8 & 282.653 & 193.470 & 0.605 & 280.172 & 189.252 & 0.613 & -0.878 & -2.180 & 1.331 \\
1.0 & 80.556 & 103.302 & 0.404 & 72.974 & 93.703 & 0.403 & -9.413 & -9.292 & -0.134 \\
\hline \multicolumn{4}{c}{ Average increasement } & & & -1.481 & -2.544 & 1.070 \\
\hline
\end{tabular}

For torque values generated by variations of PBCF 01 experienced a decrease in the entire advance coefficient variation with an average of $-2,482 \%$. The highest torque decline occurred in the $\mathrm{J} 1.0$ with a decline of up to$9,056 \%$.

The efficiency value produced by PBCF 01 variations experienced an increase in the whole variation of the advance coefficient with an average of $1,218 \%$. The highest efficiency increase occurred in $\mathrm{J} 0.2$ with an increase of $1.94 \%$.

\section{Performance Analysis of PBCF 02}

From Table 6, it can be concluded that variations of PBCF 02 thrust value tend to decrease by an average of$1,311 \%$. This is because the thrust value of $\mathrm{J} 1.0$ drops drastically to- $8,606 \%$. However, the variations of $\mathrm{J} 0.2$, 0.4 , and 0.6 thrust values continue to increase.

For torque values generated by variations of PBCF 02 decreased in the whole variation of the advance coefficient with an average of $-2,502 \%$. The highest torque decline occurred in the $\mathrm{J} 1.0$ with a decline of up to$9,124 \%$.

The efficiency value produced by PBCF 02 variation experienced an increase in the whole variation of the advance coefficient with an average of $1,211 \%$. The highest efficiency increase occurred in $\mathrm{J} 0.2$ with an increase of $1,921 \%$.

\section{Performance Analysis of PBCF 03}

From Table 7, it can be concluded that in variations PBCF 03 thrust value tends to decrease with an average of-1,336\%. This is because the thrust value of $\mathrm{J} 1.0$ drops drastically to- $8,839 \%$. However, the variations of $\mathrm{J} 0.2$, 0.4 , and 0.6 thrust values continue to increase.

For torque values generated by variations of PBCF 03 decreased in the whole variation of the advance coefficient with an average of $-2,468 \%$. The highest torque decline occurred in the $\mathrm{J} 1.0$ with a decline of up to$9,091 \%$.

The value of efficiency generated by variations of PBCF 03 experienced an increase across the variation of the advance coefficient with an average of $1,145 \%$. The highest efficiency increase occurred in $\mathrm{J} 0.2$ with an increase of $1,904 \%$.

\section{E. Performance Analysis of PBCF 04}

From Table 8 , it can be concluded that variations of PBCF 04 thrust value tend to experience a decrease with an average of $-1,481 \%$. This is because the thrust value of J 1.0 drops drastically to- $9,413 \%$. However, the variations of $\mathrm{J} 0.2,0.4$, and 0.6 thrust values continue to increase.

For torque values generated by variations of PBCF 04 decreased in the whole variation of the advance coefficient with an average of $-2,544 \%$. The highest torque decline occurred in the $\mathrm{J} 1.0$ with a decline of up to$9,292 \%$.

For the efficiency value produced by PBCF 04 Variations experienced an increase in the whole variation of the advance coefficient with an average of $1,070 \%$. The highest efficiency increase occurred in $\mathrm{J} 0.2$ with an increase of $1,940 \%$.

\section{F. Effect of Adding PBCF to Propeller Thrust}

In Figure 7, it can be seen that the thrust value after the addition of PBCF in various angles of the phase lag decreases. It is less appropriate to the concept of PBCF where it should be able to add the thrust produced by the propeller.

In that graph, it appears that the average value of the thrust drop from each variation of the phase lag angle is not much different. Thrust value of PBCF 01 variation suffered an average reduction of-1,283\%, PBCF 02 suffered an average decrease of-1,311\%, PBCF 03 suffered an average reduction of- $1,336 \%$, PBCF 04 suffered an average decrease of $-1,481 \%$.

\section{G. Effect of Adding PBCF to Propeller Torque}

In Figure 8, it can be seen that the torque value after the addition of PBCF in various phase lag angles decreases. It is already following the concept of $\mathrm{PBCF}$ where it can reduce the torque generated propeller.

On the chart, it appears that the average value of the torque-the decline in each phase-lag angle variation is not much different. The torque value in the PBCF 01 variation suffered an average reduction of $-2,482 \%$, PBCF 02 suffered an average decrease of- $2,502 \%$, PBCF 03 suffered an average reduction of $-2,468 \%$, PBCF 04 suffered an average decrease of $-2,544 \%$.

\section{H. Effect of Adding PBCF to Propeller Efficiency}

In Figure 9 It can be seen that the value of efficiency after the addition of PBCF in various phase lag angles has 
increased. It is already following the concept of PBCF where it can increase the efficiency of propeller generated. Although the thrust value tends to drop the torque value occurs a greater decline. Thus, the value of efficiency increases.

On the chart, it is apparent that the average value of the efficiency increase from each variation of the phase lag angle is not much different. The value of improvement in PBCF 01 variation experienced an average increase of $1,218 \%$, PBCF 02 experienced an average increase of $1,211 \%$, PBCF 03 experienced an average increase of $1,145 \%, \mathrm{PBCF} 04$ experienced an average increase of $1.07 \%$. addition of some of the PBCF variations simulated in the J 0.8 condition can be seen in Figures 10 to 14 .

Can be seen that the addition of PBCF can affect the propeller flow. The flow in Figure 10 forms a dizzying vortex to the center or called a vortex hub phenomenon. While in Figure 11 to 14 pictures, the flow began to widen in other words the phenomenon of the vortex hub began to disappear because it was successfully reused into rotary energy.

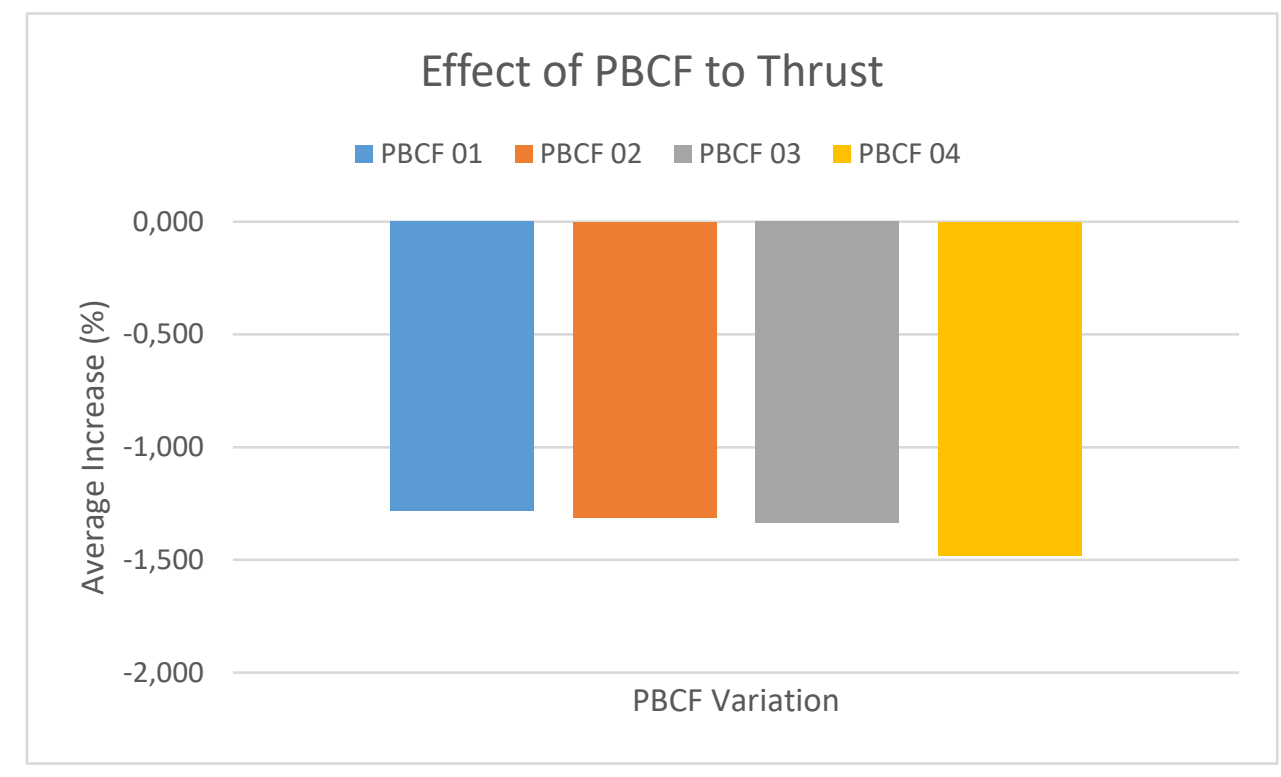

Figure. 7. Effect of PBCF to propeller thrust.

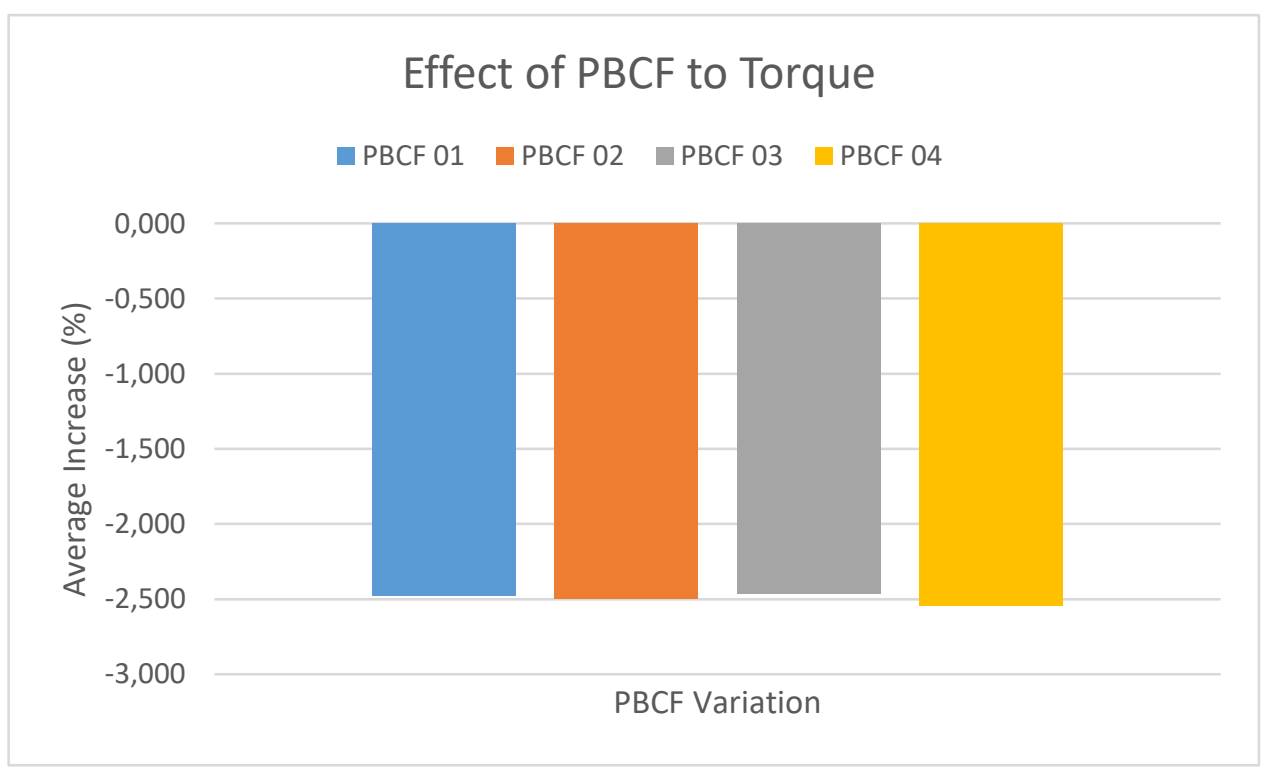

Figure. 8. Effect of PBCF to Propeller Torque.

\section{Effect of Adding PBCF to Propeller Fluid Flow}

This research analyzed the addition of the PBCF effect on the resulting flow. Here are the results of the flow of the propeller INSEAN E-1619 before and after the 
International Journal of Marine Engineering Innovation and Research, Vol. 6(2), June. 2021. 140-151 (pISSN: 2541-5972, eISSN: 2548-1479)

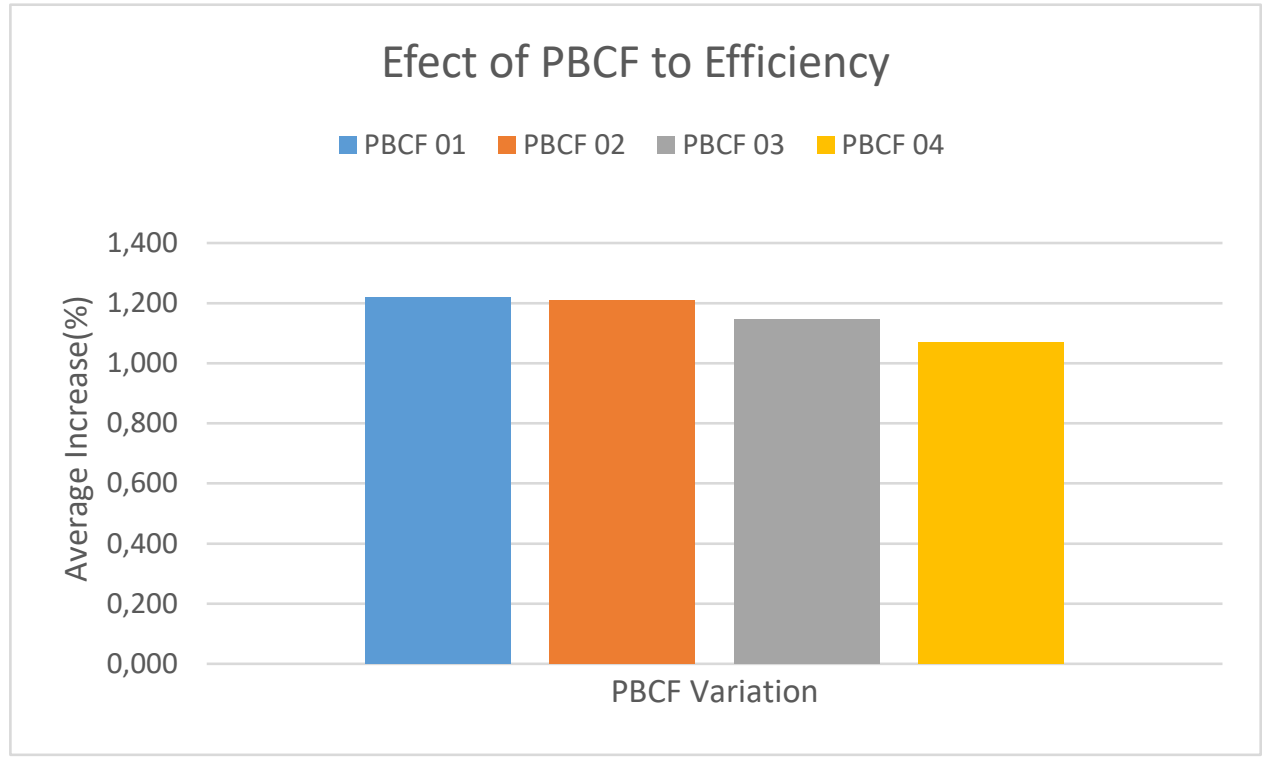

Figure. 9. Effect of PBCF to propeller efficiency.

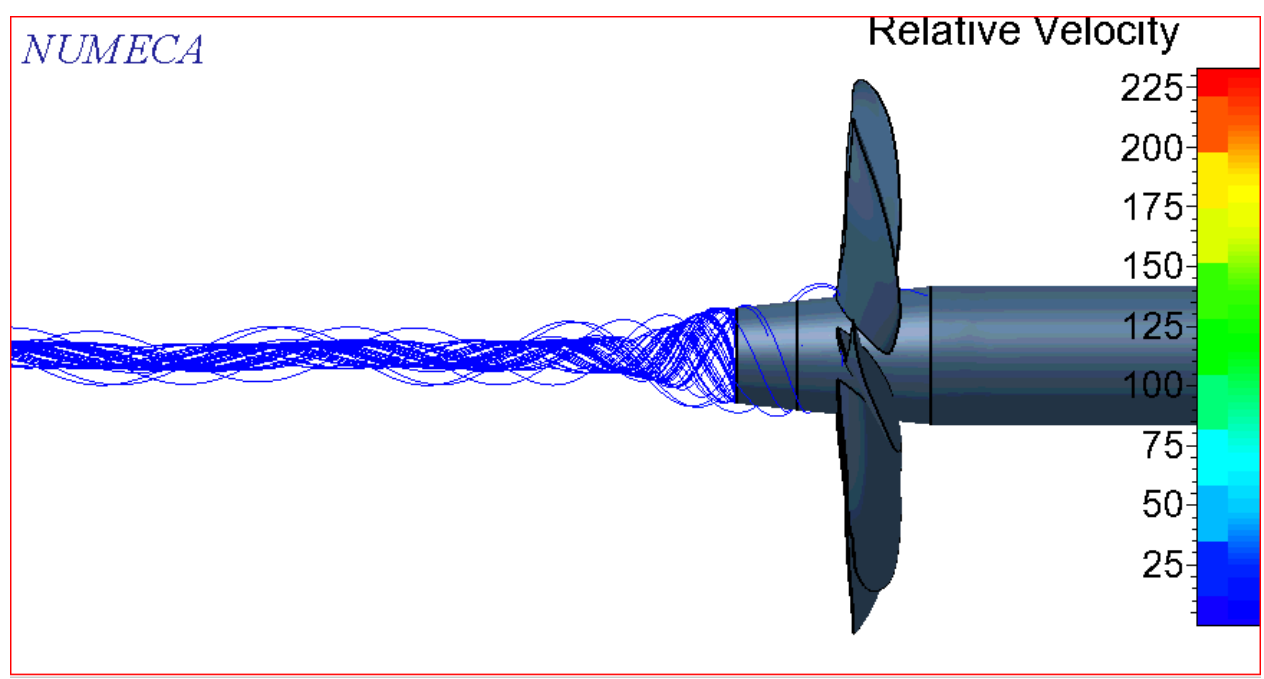

Figure. 10. Fluid flow of propeller INSEAN E-1619.

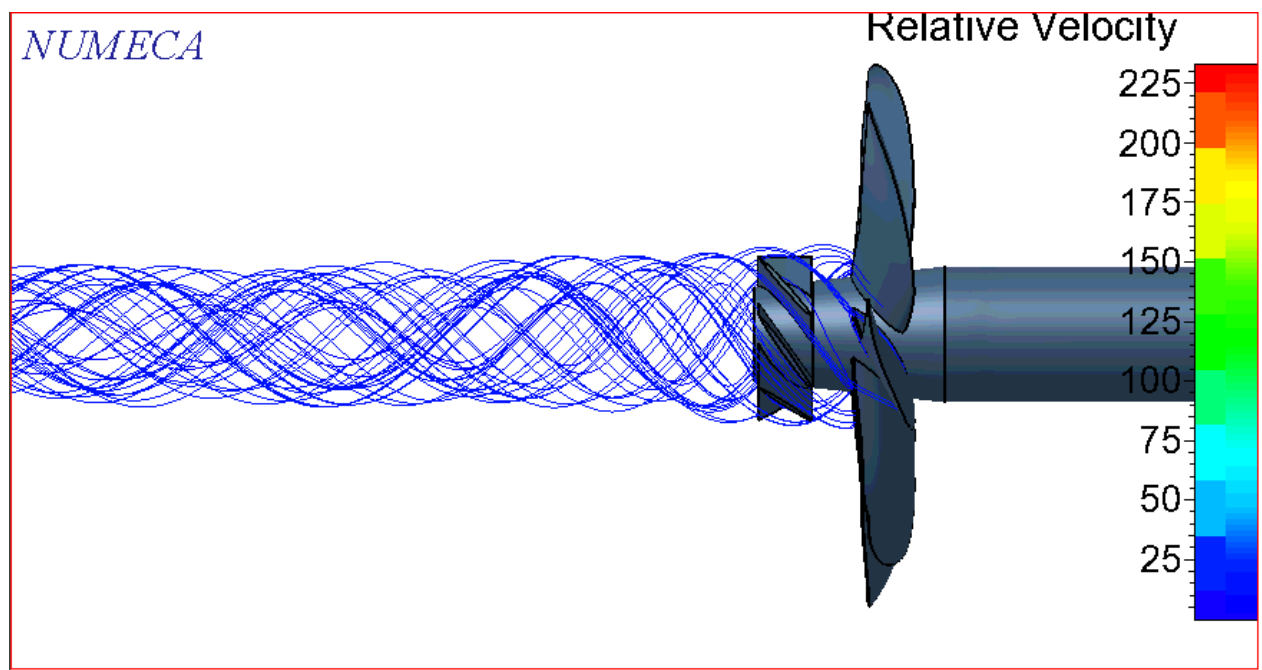

Figure. 11. Fluid flow of PBCF 01. 
International Journal of Marine Engineering Innovation and Research, Vol. 6(2), June. 2021. 140-151 (pISSN: 2541-5972, eISSN: 2548-1479)

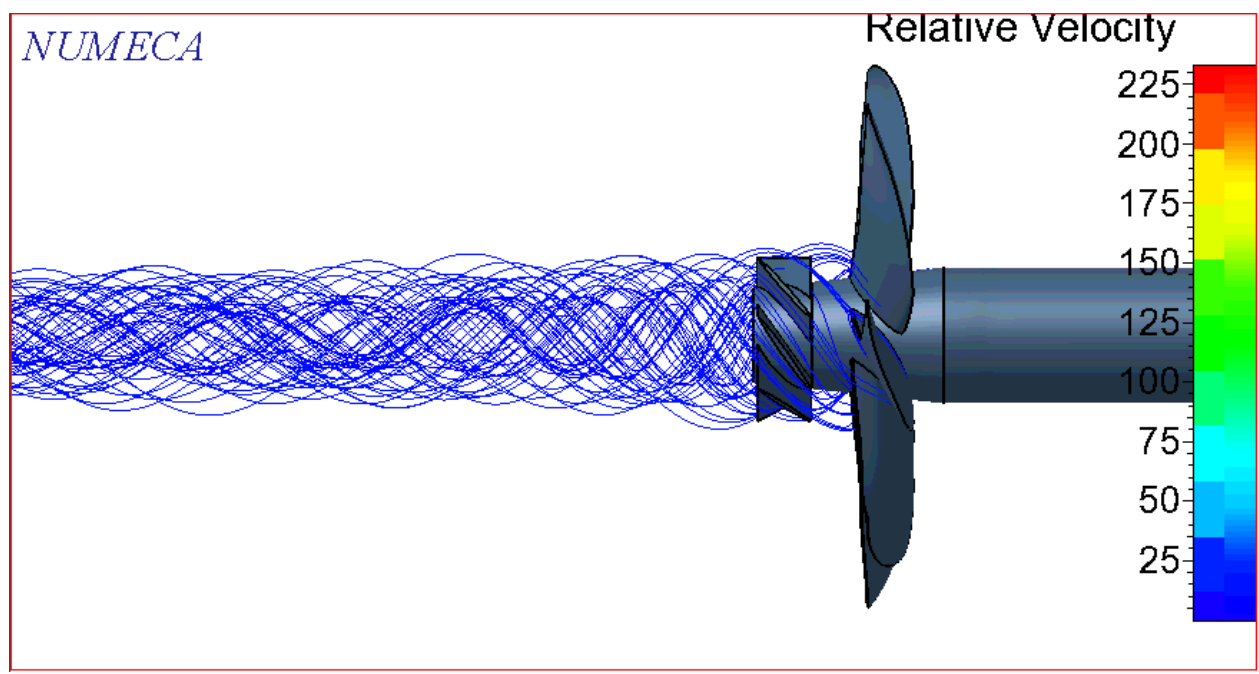

Figure. 12. Fluid flow of PBCF 02.

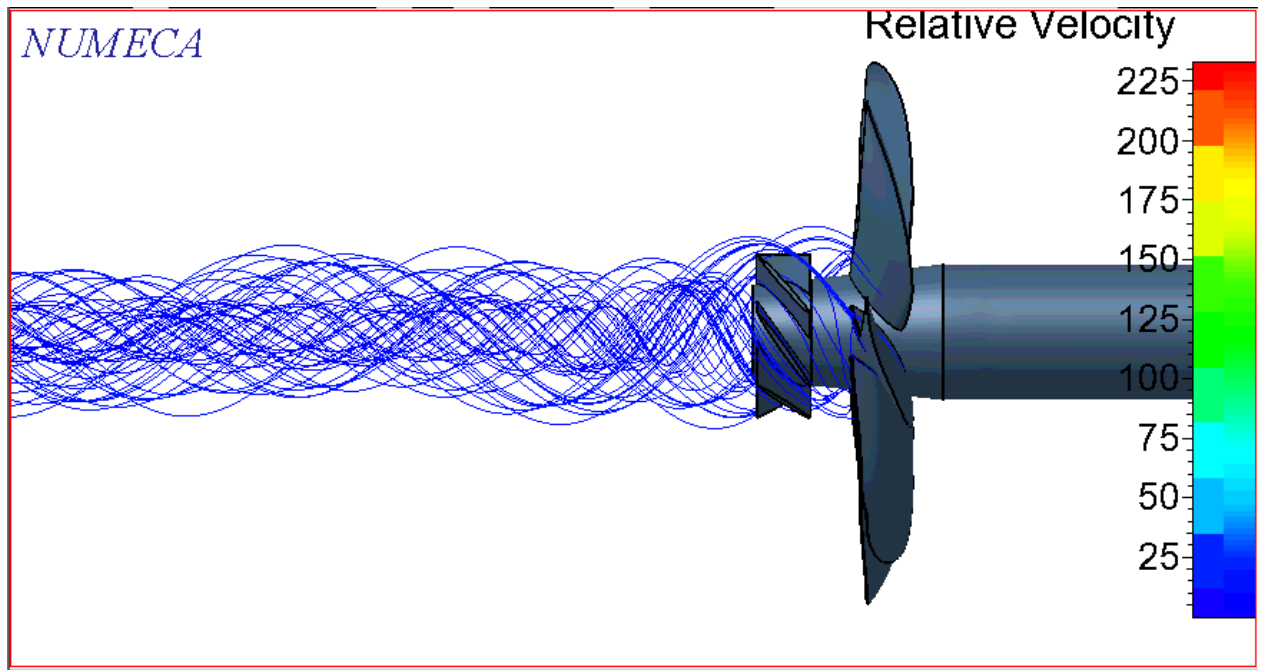

Figure. 13. Fluid flow of PBCF 03.

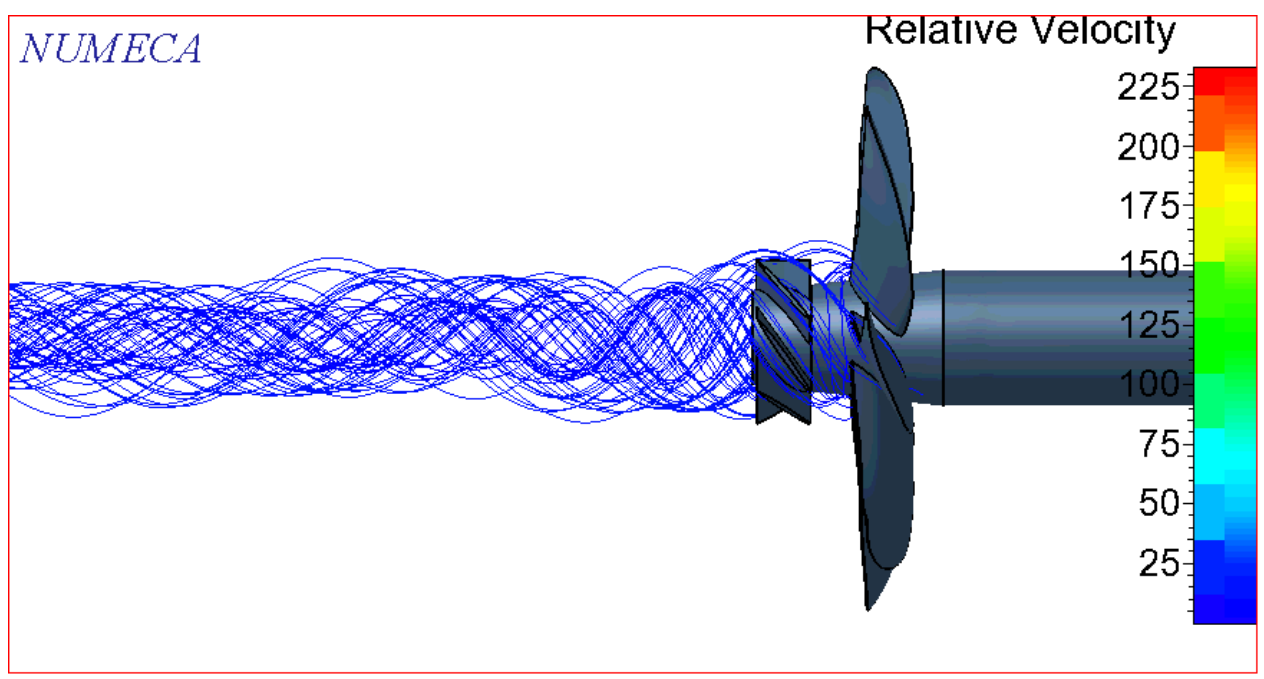

Figure. 14. Fluid flow of PBCF 04. 


\section{CONCLUSION}

From the results of the research that has been done, the author drew several conclusions as follows:

1. The addition of PBCF in all variations of the phase lag angle can increase efficiency and reduce the propeller torque. It is already following the concept of PBCF where it can increase thrust, reduce torque, and improve propeller efficiency. However, this research on the thrust value of $\mathrm{J} 0.8$ and $\mathrm{J} 1.0$ tends to decline.

The propeller performance of both thrust, torque, and efficiency produced in each variation of the phase lag angle is not much different. At a variation of PBCF 01 (phase lag $0^{\circ}$ ) occur average - average decrease thrust by$1,283 \%$, torque decrease by-2,482\%, and an increase in efficiency by $1,218 \%$. At a variation of PBCF 02 (phase Lag $12.86^{\circ}$ ) occur average - average decrease thrust by$1,311 \%$, torque decrease by-2,502\%, and increased efficiency by $1,211 \%$. In the PBCF 03 (phase Lag 25.72 $\left.{ }^{\circ}\right)$ variation There was an average reduction in thrust of$1,336 \%$, a torque decrease of $-2,468 \%$, and an increase in efficiency by $1,145 \%$. At a variation of PBCF 04 (phase Lag $38.58^{\circ}$ ) occurred average - average decrease thrust by- $1,481 \%$, torque decrease by- $2,544 \%$, and increased efficiency by $1,070 \%$.

2. The addition of PBCF across the range of phase lag angles is very effective in reducing the hub vortex.

\section{REFERENCES}

[1] IMO, "Low Carbon Shipping and Air Pollution Control," International Maritime Organization, 2013. [Online]. Available: http://www.imo.org. [Accessed 18 2020].

[2] M. A. F. Chekab, P. Ghadimi and M. Soroushan , "Investigation of Different Methods of Noise Reduction for Submerged Marine Propellers and Their Classification," American Journal of Mechanical Engineering, vol. 1, pp. 34 - 42, 2013.

[3] G. Kuiper, THE WAGENINGEN PROPELLER SERIES, Netherlands: MARIN Publication, 1992.

[4] A. F. N. Oloan, "Analisa Pengaruh Penambahan Boss Cap Fins pada Propeller B-Series dengan Pendekatan Metode CFD," Departemen Teknik Sistem Perkapalan ITS, Surabaya, 2018.

[5] H. Yudo and S. Jokosisworo, "STANDAR KEBISINGAN SUARA DI KAPAL," Program Studi Teknik Perkapalan Fakultas Teknik Universitas Diponegoro, Semarang, 2012.

[6] E. Miasnikov, What is known about the character of noise created by submarines?, The Future of Russia's Strategic Nuclear Forces: Discussions and Arguments, ed., fas.org, 1998.

[7] K. Ouchi, M. Ogura, M. Tamashima and H. Koizuka, "A research and development of PBCF (propeller boss cap fins)-improvement of flow from propeller boss," Journal of the Society of Naval Architecture of Japan, vol. 163, pp. 66-78, 1988

[8] L. MOL Techno-Trade, "Energy saving device - Propeller boss cap fins," 2018. [Online]. Available: http://pbcf.jp. [Accessed Januari 2020].
[9] M. I. Nanda, ANALISA PENGARUH VARIATION SUDUT SKEW PROPELLER B-SERIES TERHADAP PERFORMA DAN KAVITASI MENGGUNAKAN METODE CFD, Surabaya: Departemen Teknik Sistem Perkapalan - ITS, 2019.

[10] S. Burunsuz, M. C. Ozden and Y. A. Ozden, "Four Quadrant Thrust and Torque Prediction of INSEAN E-1619 Generic Submarine Propeller for Submarine Maneuvering Simulations," Fifth International Symposium on Marine Propulsors , 2017.

[11] E. L. Schwer, Is Your Mesh Refined Enough? Estimating Discretization Error Using GCI, Bamberg: LS-DYNA Anwenderforum, 2008.

[12] K. Mizzi, Y. K. Demirel and C. Banks, "Design Optimisation of Propeller Boss Cap Fins for Enhanced Propeller Performance," Applied Ocean Research, no. 62, pp. 210-222, 2017.

[13] C. Y. Hsin, B. Lin and C. C. Lin, "The Optimum Design of a Propeller Energy Saving Device by Computational Fluid Dynamics," Computation Fluid Dynamics, 2009.

[14] S. -. S. Lim, T. -. W. Kim, D. -. M. Lee and S. -. Y. Kim, "PARAMETRIC STUDY OF PROPELLER BOSS CAP FINS FOR CONTAINER SHIPS," International Journal of Naval Architecture and Ocean Engineering, vol. 6, pp. 187 - 205, 2014.

[15] S. Gaggero, "Design of PBCF Energy Saving Devices using Optimization Strategies," Ocean Engineering, vol. 159, pp. 517$538,2018$.

[16] I. Fikry, "ANALISA PENGARUH PERUBAHAN SPAN TO CHORD RATIO PROPELLER BOSS CAP FINS PADA PROPELLER WAGENINGEN SERIES C4-40 DENGAN METODE CFD," Departemen Teknik Sistem Perkapalan ITS, Surabaya, 2019.

[17] J. Scott, "NACA Airfoil Series," 2001. [Online]. Available: http://www.aerospaceweb.org/question/airfoils/q0041.shtml. [Accessed 5 Mei 2020].

[18] J. Carlton, MARINE PROPELLERS AND PROPULSION, Second ed., Great Britain: Elsevier Ltd., 2007.

[19] H. E. Cleary, " The Effects of Reynolds Number on the Application of NACA 16-Airfoil Characteristics to Propeller Design," NACA TN 2591, 1952.

[20] ITTC, "ITTC-Recommended Procedures," Open Water Test, p. 8, 2014.

[21] "Airfoil Tools," [Online]. Available: http://airfoiltools.com/airfoil/details?airfoil=naca16006-il. [Accessed 10 Mei 2020].

[22] S. Khasnabis, "Different Ways To Reduce Ship Propeller Vibrations And Increase Its Efficiency," marine insight, 6 February 2020. [Online]. Available: www.marineinsight.com. [Accessed 15 Mei 2020]. 